\title{
Reconstrucciones históricas del puente de El Kantara en Constantine, Argelia
}

\section{Historical reconstructions of the "El Kantara" Bridge at Constantine, Algiers}

\author{
J. Bernabeu-Larena $^{(*)}$, A. Meghraoui ${ }^{(* *)}$, P. Hernández-Lamas ${ }^{(*)}$
}

\section{RESUMEN}

Constantine, conocida como la «ciudad de los puentes», reúne un patrimonio construido excepcional. Entre sus puentes, se analiza como obra especialmente significativa el de «El Kantara» y sus reconstrucciones históricas: desde el primer puente romano de piedra del año 161, hasta el actual arco de hormigón armado que data de 1951, pasando por la reconstrucción otomana de 1792 y el arco de ingeniería francesa de hierro de 1863. El artículo reúne referencias históricas y documentales de sus diferentes configuraciones. Las sucesivas soluciones ponen de manifiesto la evolución tecnológica de la construcción de puentes, a la vez que muestran su incidencia en la transformación urbana y en la propia identidad de la ciudad.

Palabras clave: Puentes; patrimonio; diseño estructural; evolución tecnológica; proceso constructivo; identidad cultural.

\section{ABSTRACT}

Constantine, known as the "city of bridges", has an exceptional built heritage. Among its bridges, is analyzed as particularly significant the historical reconstructions of "El Kantara": from the first Roman stone bridge, dated 161, up to the current concrete arch built in 1951, through the Ottoman rebuilding of 1792 and the cast iron French bridge of 1863. The article brings together historical and documentary references of its different configurations. Successive solutions reflects the technological evolution of bridges, while showing its impact on urban transformation and in the construction of the city's identity.

Keywords: Bridges; heritage; structural design; technological evolution; construction process; cultural identity.

(*) ETSI Caminos, Canales y Puertos - Universidad Politécnica de Madrid (España).

(**) Dép. d'Architecture - École des Mines d'Alès (Francia).

Persona de contacto/Corresponding author: jorge.bernabeu@upm.es (J. Bernabeu-Larena)

Cómo citar este artículo/Citation: Bernabeu-Larena, J., Meghraoui, A., Hernández-Lamas, P. (2015). Reconstrucciones históricas del puente de El Kantara en Constantine, Argelia. Informes de la Construcción, 67(540): e120, doi: http://dx.doi.org/10.3989/ic.15.034.

Licencia/License: Salvo indicación contraria, todos los contenidos de la edición electrónica de Informes de la Construcción se distribuyen bajo una licencia de uso y distribución Creative Commons Reconocimiento no Comercial 3.o. España (cc-by-nc). 


\section{INTRODUCCIÓN}

Los puentes son mucho más que obras que salvan un obstáculo. Su significación cultural y su fuerte impacto en la evolución urbana los convierten en construcciones que amplían su función más allá de lo tecnológico para reunir significados y dotar de identidad a los lugares en que se ubican. Tal es el caso, especialmente significativo, de la ciudad de Constantine, en Argelia. La ciudad ocupa un enclave natural estratégico sobre una plataforma rocosa de calizas, rodeada por las gargantas del río Rhumel en el extremo norte y este, y un escarpe vertical en el oeste. Su privilegiada disposición territorial y defensiva ha hecho de ella una de las más antiguas ciudades del Magreb, donde se instalaron fenicios, númidas, romanos, vándalos, árabes, otomanos y franceses. A lo largo de su historia, las diferentes culturas han construido puentes, constituyendo una colección patrimonial excepcional; no en vano, Constantine es conocida como «la ciudad de los puentes» (1).

Para poner en valor su importancia histórica y cultural, así como su relevancia en la evolución de la ciudad, el artículo se centra en su puente más antiguo: el conocido como «El Kantara», de origen romano, que ha sufrido a lo largo de su historia destrucciones y reconstrucciones sucesivas, las cuales permiten seguir el progreso tecnológico, sobre todo en las etapas más significativas en relación a la historia de la construcción de puentes. El presente trabajo localiza y reúne las diferentes referencias bibliográficas de cada una sus reconstrucciones, con el objetivo de trazar una evolución que atiende a sus valores tecnológicos y patrimoniales.

\section{CONSTANTINE, LA CIUDAD DE LOS PUENTES}

El desarrollo de la ciudad de Constantine ha estado siempre relacionado con los puentes que le dan acceso (2). La meseta caliza, sobre la que se sitúa la ciudad, ha sido erosionada por el río; conforma una brecha natural que alcanza los $300 \mathrm{~m}$ de altura. A lo largo de la historia, los puentes han ido aumentando en luz y en altura, estableciendo comunicaciones en puntos nuevos y en niveles más altos. La cota a la que se sitúan las estructuras es un parámetro esencial en su solución tipológica, y queda determinada por las posibilidades tecnológicas y constructivas de la época. Los arcos de piedra, solución tipológica y constructiva durante miles de años, fueron aumentando luces y rebajando alzados, reconstruyéndose una y otra vez sobre los anteriores. A principios del siglo XX, los puentes colgantes introdujeron una nueva tipología que permitió conectar los niveles superiores a nuevos accesos. Y ahora, en el XXI, un puente atirantado cruza el valle del Rhumel, ofreciendo una nueva conexión.

El puente de El Kantara es el primero y más antiguo de los accesos a la ciudad sobre el río. Pero no es una estructura aislada; forma parte de un conjunto patrimonial de puentes, que es necesario conocer someramente para situar en su contexto (Figura 1).

A lo largo de la brecha de Rhumel, el cauce ha formado varias bóvedas naturales que, a modo de puentes, conectan las márgenes del barranco en ciertos puntos, a unos $50 \mathrm{~m}$ de altura. Estos puentes naturales se mantienen desde antaño y conviven con los construidos. Mientras que los primeros son de difícil acceso y no ofrecen continuidad a los caminos, los segundos han permitido la conexión y el crecimiento de la ciudad fuera de sus límites.
Cruzan el cauce varios puentes arco de piedra de épocas diversas. De la mayoría, quedan hoy únicamente sus ruinas en las márgenes del río. Se mantienen en servicio el Pont des Chutes, puente de las cataratas, en su reconstrucción de 1925, y el puente de Sidi Rached, construido en 1912, ejemplo excepcional de la tardía ingeniería francesa de fábrica (Figura 1a): el trazado en planta se quiebra para buscar los mejores apoyos, mientras que, en alzado, 27 arcos de piedra ofrecen luces diferentes según las zonas y los obstáculos a salvar. El vano principal tiene 70 m de luz, y en su construcción intervino Paul Sejournée.

Dos puentes colgantes permiten conectar las cotas altas de la ciudad con nuevos accesos: el puente de Sidi M'Sid, de $125 \mathrm{~m}$ de luz, a 180 m de altura sobre el Rhumel, construido en 1912 (Figura 1b), y la pasarela peatonal de Perrégaux, de $100 \mathrm{~m}$ de luz, construida en 1925. Constantine cuenta con dos puentes recientes: uno de hormigón pretensado, de ingeniería italiana, construido por voladizos sucesivos sobre el que circula el tranvía desde 2013, y el viaducto de Trans-Rhumel, un puente atirantado, proyectado por Cowi, construido por la empresa brasileña Andrade Gutiérrez e inaugurado en 2014 (Figura 1c). Este último es imagen del proceso de renovación de la ciudad de Constantine, capital cultural del mundo árabe en 2015, y representa el impulso de modernización del conjunto del país.

\section{CUATRO PUENTES EN UN MISMO EMPLAZAMIENTO}

\subsection{El puente romano de Antonino Pío (161)}

Constantine es la antigua Cirta, capital numidia en el siglo III a. C. Aprovecha su emplazamiento natural defensivo para
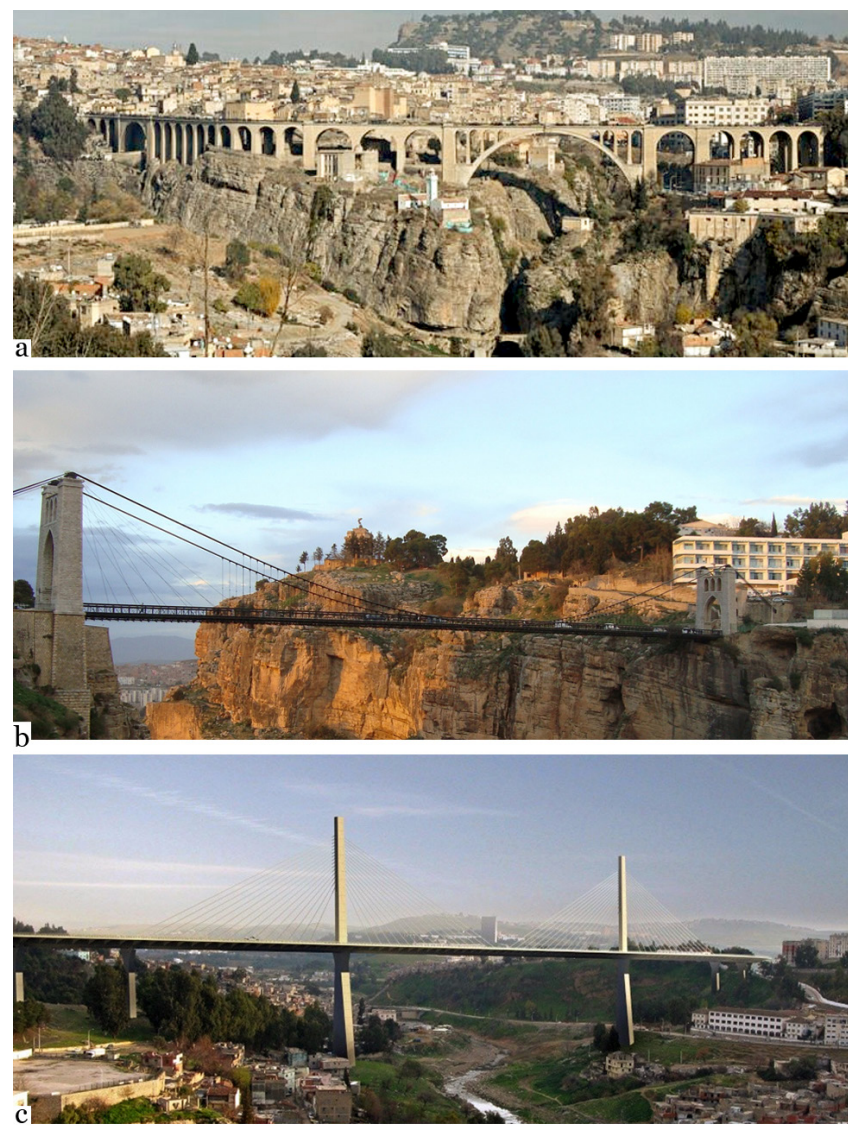

Figura 1. Tres ejemplos del patrimonio de puentes de Constantine: el puente de Sidi Rached (1912); el puente suspendido de Sidi M'Sid (1912) y el nuevo puente atirantado de Trans-Rhummel (2014). 
establecer una ciudad fortificada y comercial, con una posición estratégica en las comunicaciones de la región. Cirta se incorpora al imperio romano con la tercera guerra púnica en el año 112 a. C. Bajo el gobierno del emperador Antonio Pío (138-161), se acomete la construcción de la primera conexión permanente sobre el río.

El primer puente de piedra disponía, según el geógrafo árabe del siglo XII Al Idrisi (3), de tres niveles de bóvedas superpuestos: cinco arcos en el superior, tres arcos en el inferior y unas pequeñas arcadas en el nivel intermedio, que favorecían el desagüe en caso de avenidas. El puente incorporaba también un acueducto que abastecía en sifón a la ciudad desde la zona norte de Bou Merzoug, y una puerta monumental, una de las dos que daban acceso a la ciudad (4). El puente se situaba en un pequeño estrechamiento del barranco, y se cimentaba sobre una bóveda natural bajo la que discurría el río (Figura 2). El emplazamiento aprovechaba, por una parte, la menor anchura de la cerrada en ese punto y, por otra, la elevación de la bóveda natural, de potente espesor calizo, a $50 \mathrm{~m}$ por encima del nivel del río.

La estructura tenía unas dimensiones de más de $50 \mathrm{~m}$ de altura y $60 \mathrm{~m}$ de longitud; las luces de los arcos principales no alcanzaban los $10 \mathrm{~m}$. Algunos autores establecen analogías entre la composición en niveles y las diferencias en número y dimensiones de los arcos con el Pont du Gard, el acueducto romano del siglo I situado en el sur de Francia (5) (6). En la actualidad se conservan únicamente las pilas y dos arcos del nivel inferior. En la parte inferior de una de las pilas quedan fragmentos de inscripciones de grandes dimensiones, con caracteres de hasta $37 \mathrm{~cm}$ de altura, dedicadas a Antonino Pío (4). En la cara norte, en la parte superior de la pila central, un bajorrelievesobrerelieve? reproduce la imagen de dos elefantes enfrentados en actitud de lucha o vigilancia de los extremos del puente, coronados por una figura femenina (Figura 3 ), que constituye otro testimonio de la época (7).

Guy de Mauppassant, en sus Carnets de Voyage de 1884 (8), se refiere al puente romano: «Ocho puentes atravesaban el precipicio. Seis de ellos están hoy en ruinas. Uno solo, de origen romano, nos da aún idea de lo que fue. El Rhumel, de sitio en sitio, desaparece bajo arcos colosales que él mismo excava. Sobre uno de ellos fue construido el puente. La bóveda natural por donde pasa el río se eleva $41 \mathrm{~m}$, su espesor es

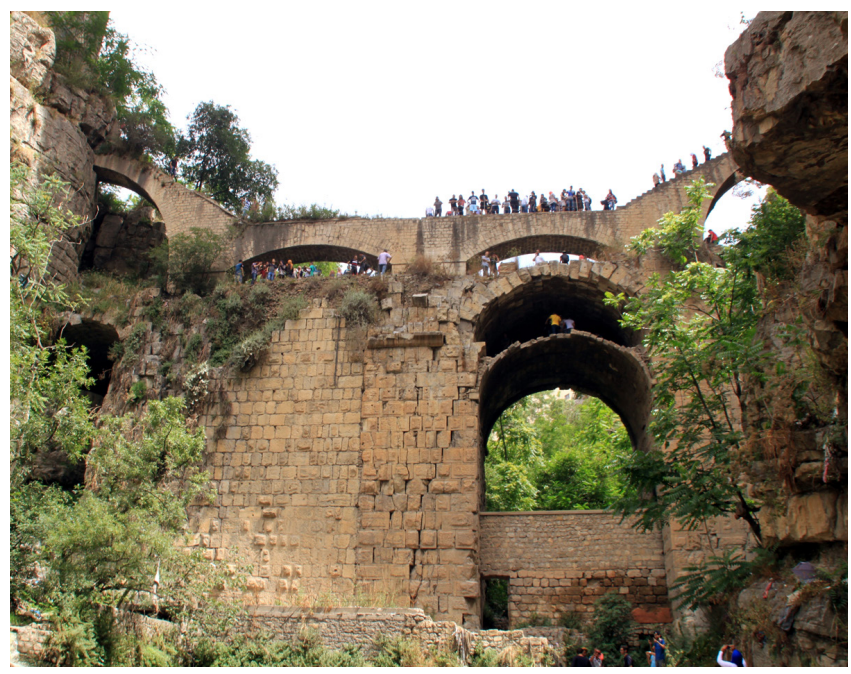

Figura 2. Vestigios del puente romano de Antonio Pío. de $18 \mathrm{~m}$; los cimientos de la construcción romana están por tanto a $59 \mathrm{~m}$ sobre el agua».

En el año 313, bajo el gobierno del emperador Constantino, se renovó la ciudad, se construyeron nuevos puentes, y cambió el nombre de Cirta por Constantine, en memoria del emperador. En 1185, todos los puentes romanos, a excepción de El Kantara, fueron destruidos. A comienzos del siglo XIV, en 1302, con la ciudad incorporada a Túnez bajo la dinastía de los Hafsidas, el puente El Kantara fue demolido en la contienda de Ibn-el-Amir (9). El paso quedó interrumpido durante casi 5 siglos, sin acceso a la ciudad sobre las gargantas del Rhumel.

\subsection{La reconstrucción de Salah Bey (1792)}

A partir del siglo XVI, Constantine queda bajo dominación turca. Entre 1771 y 1792 el Bey Salah, uno de los más célebres gobernantes de la ciudad, impulsó un buen número de obras de urbanización y mezquitas. Confió la reconstrucción del puente romano al constructor balear Bartolomeo. Para llevarla a cabo, se partió de las cimentaciones y ruinas del antiguo puente, y se completó con piedra procedente de las ruinas del antiguo anfiteatro romano. El puente reproduce aproximadamente la configuración del original romano. La nueva reconstrucción reduce el número de arcos, maciza los arquillos del nivel intermedio y reestablece también el sifón que abastece a la ciudad desde Djebel Ouahch.

La reconstrucción turca queda recogida en el testimonio de Charboneau, de 1853 (10): «La construcción, tal como la vemos hoy, se erigió en 1788 y 1789 bajo el principado de Salah Bey por un ingeniero balear. Tiene dos niveles. El nivel inferior se compone de dos arcos; uno de ellos, próximo a la ciudad, se macizó en época desconocida. Los dos arcos quedan sustentados por tres pilas cuya estructura es evidentemente romana, desde la base hasta la cornisa. En el segundo nivel, que se eleva 16 metros sobre el piso inferior, se compone de cuatro arcos. Los dos centrales se apotan sobre los arcos inferiores; sus bóvedas son ojivales, mientras que los laterales son bóvedas circulares y visiblemente más grandes. La altura del puente alcanza los 65 metros; el tablero tiene 60 metro de largo».

Se evidencian así las similitudes entre la descripción y las imágenes documentales de mediados del XIX: las tomadas

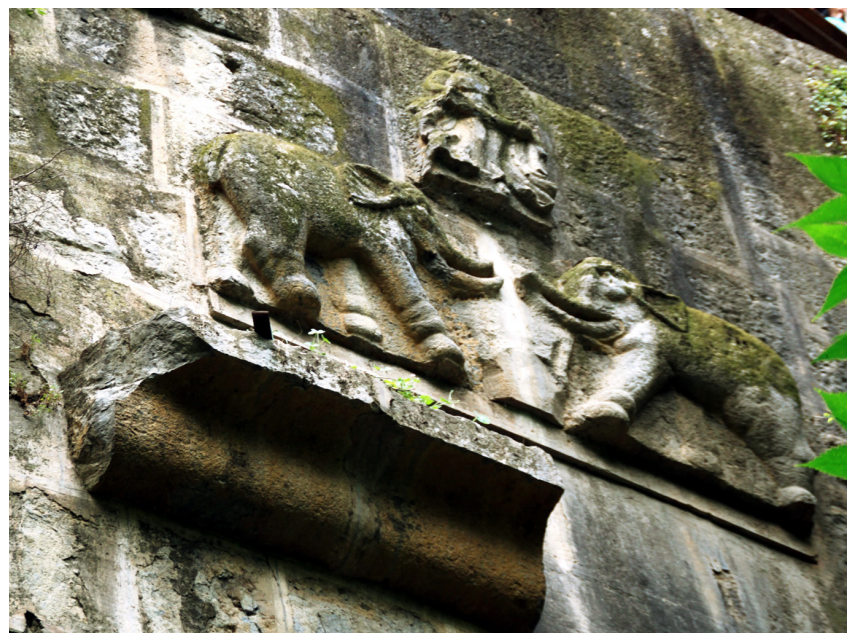

Figura 3. Bajorrelieve de dos elefantes coronados por una figura femenina. 
en 1856 por John Beasley Greene, fotógrafo y arqueólogo conocido por sus viajes a Egipto y Oriente (Figura 4), y las de Félix-Jacques Moulin, de su viaje fotográfico financiado por Francia, con apoyo de las autoridades coloniales, que publicó en 1858 en el libro L'Algérie photographiée (Figura 5).

El puente, 65 años después de su nueva inauguración, sufrió una tragedia. El 18 de marzo de 1857 se derrumbó al paso de un destacamento de infantería (11). Los dos primeros arcos del puente, lado ciudad, se hundieron, dejando un hueco de $21 \mathrm{~m}$. El acueducto también quedó afectado, y la ciudad perdió su abastecimiento de agua. El 27 de marzo de 1857, de acuerdo con el relato de M. E. Mercier, alcalde de Constantine, los cañones del ejército francés abrieron fuego contra lo que quedaba en pie del puente. Se necesitaron cuarenta cañonazos para abatir la antigua fábrica romana. Termina el testimonio: «Este fue el final del puente que había sido reparado por Bartolomeo, por encomienda de Salah Bey. Su demolición permitió recuperar los restos de una inscripción con las palabras Hadriani Filio -Hijo de Adriano-, demostración de que el puente fue construido o reparado originalmente durante el reinado de Antonino Pío» (10).

\subsection{El arco metálico de Napoleón III (1863)}

La reconstrucción francesa del puente de 1863 es la mejor documentada con planos, notas de cálculo y descripciones del proceso constructivo, tanto en publicaciones (5) como en apuntes de obra (12) y documentación fotográfica.

La reconstrucción del puente, emprendida por la administración francesa de Ponts et Chaussées en el reinado de Napoleón III, comenzó con la encomienda de 1860, tras la visita a la ciudad del ministro francés para Argelia y las colonias junto con el inspector general de Ponts et Chaussées, y fue encargada al ingeniero Georges Martin.

Tras los estudios preliminares, se optó por una solución formada por dos tramos de acceso de fábrica y otro central, con estructura metálica de arco. «Se compone de dos pilas estribo de fábrica construidas sobre cada una de las márgenes del barranco, y unidas por un arco de fundición de $56 \mathrm{~m}$ de luz. $\mathrm{Su}$ tablero presenta una anchura entre barandillas de $10 \mathrm{~m}$ repartidos entre una calzada de $6 \mathrm{~m}$ y dos aceras de $2 \mathrm{~m}$. La

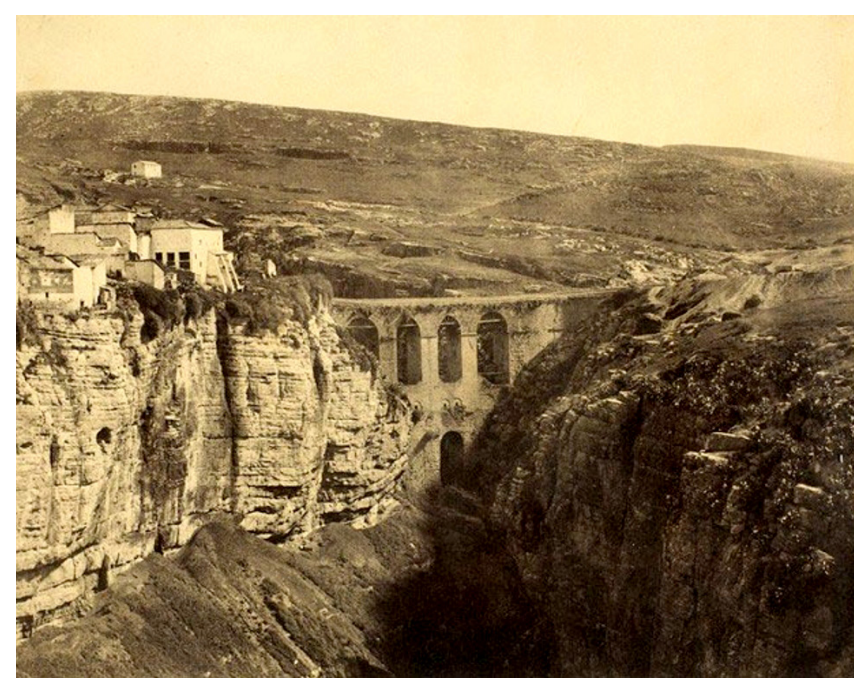

Figura 4. El puente de Salah Bey. Fotografía: John Beasly Green, 1856.

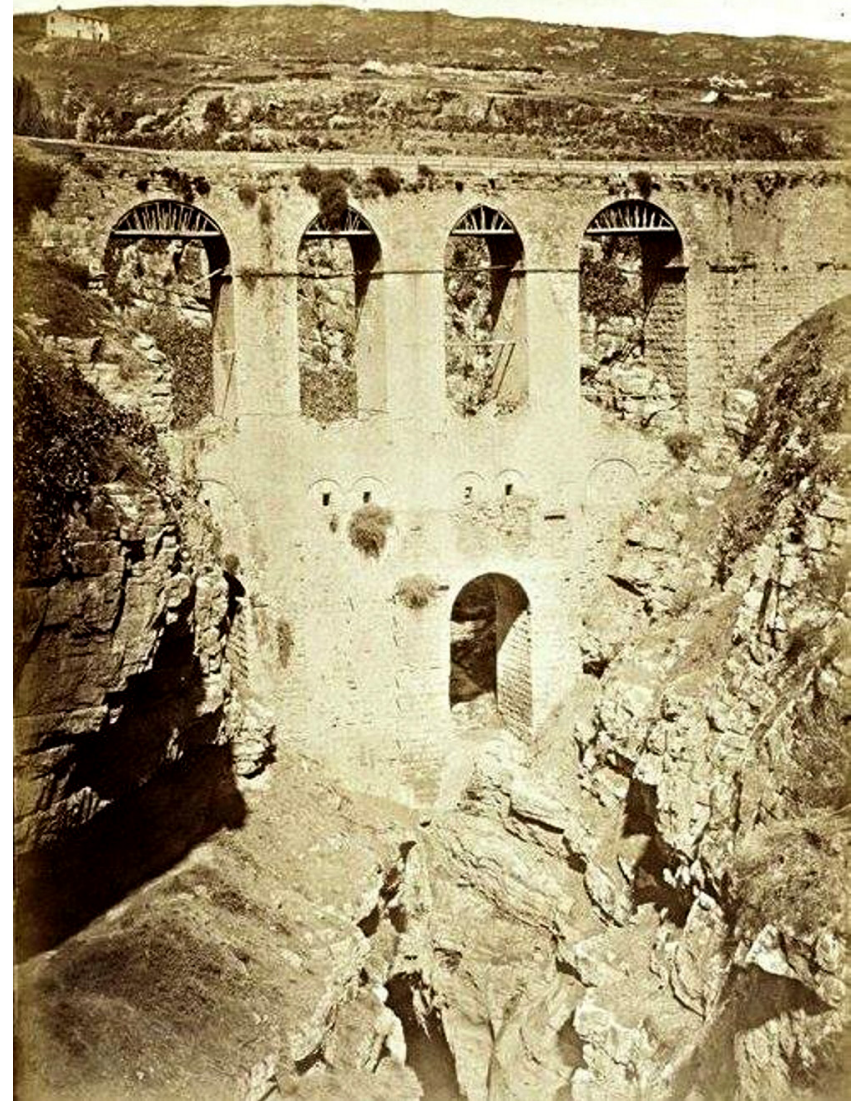

Figura 5. El puente de Salah Bey. Fotografía: Félix-Jacques Moulin, 1858.

estructura metálica está compuesta por cinco arcos de fundición arriostrados por veinticinco celosías, y tímpanos en el plano bajo la calzada. El tablero está formado por vigas de fundición de $2 \mathrm{~m}$ de luz entre arcos» (5). Los tímpanos presentan una celosía de fundición con geometrías circulares, rodeadas de seis radios, que se van adaptando a la variación de canto (Figura 6).

La rasante se elevó más de $10 \mathrm{~m}$ para conectar con la nueva rue Nationale y el barrio que lleva su nombre, el Bab El Kantara. En el momento de su construcción y puesta en servicio, la calzada carecía de continuidad con ninguna vía rodada. La rue Nationale se completó en 1968 con intención de atravesar la ciudad vieja y comunicar con la plaza de la Brèche, asegurando así una conexión directa de la ciudad histórica con la futura estación ferroviaria (1870), próxima al puente de El Kantara en la margen exterior, y la carretera de circunvalación de la Corniche (Figura 7). En planta tampoco mantiene la alineación de las anteriores. Se sitúa varios metros aguas arriba de las antiguas cimentaciones romanas, para confluir con la nueva calle.

$\mathrm{Al}$ igual que sus predecesores, el puente alberga también un sifón para el abastecimiento de agua de la ciudad. Los $56 \mathrm{~m}$ de luz permiten que la estructura se apoye directamente en las laderas del barranco, sin cargar sobre la bóveda natural como sus predecesoras (Figura 8). La longitud en coronación de la nueva estructura es de $128 \mathrm{~m}$, y sitúa la cota de la plataforma a $120 m$ de altura sobre las aguas del Rhummel.

La construcción a dicha altura, con las pronunciadas pendientes del barranco y las dificultades de acceso, se realizó mediante una cimbra de madera suspendida, de cables de hierro 


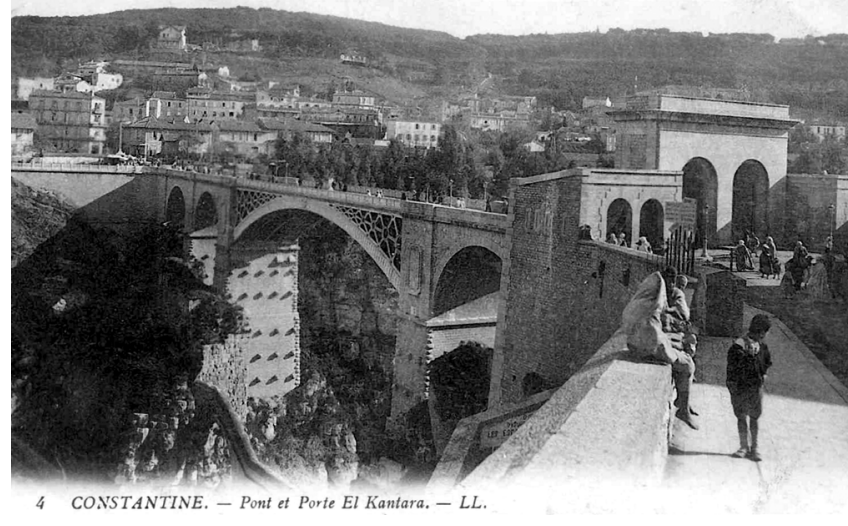

Figura 6. Postal de época con el arco metálico y la puerta de El Kantara.

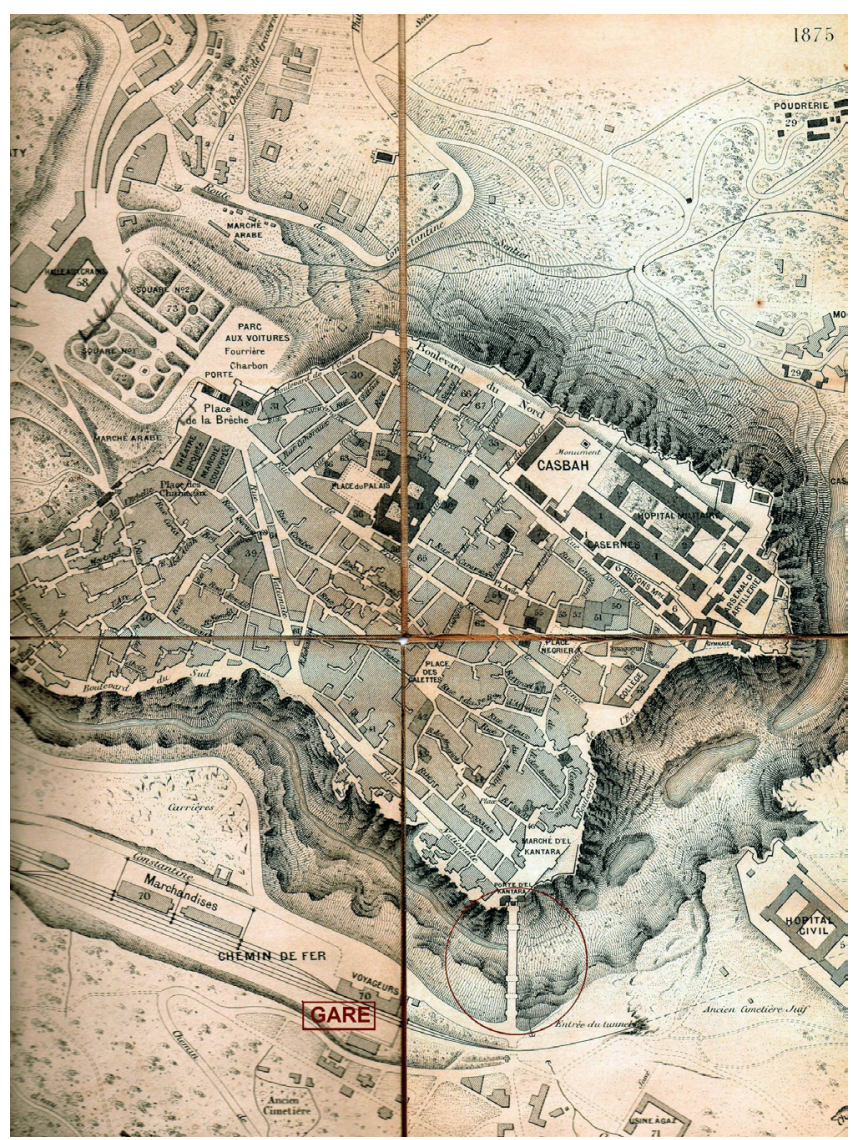

Figura 7. Plano de Constantine en 1875. En la zona inferior se señala con un círculo rojo el puente de El Kantara, que asociaba la nueva estación ferroviaria y la rue Nationale.

(Figuras 8 y 9). Los cables se anclaban sobre sendos caballetes de madera y fundición dispuestos en la coronación de las pilas, estribo de fábrica. Sobre el arco de madera se disponían las dovelas de fundición, construidas y transportadas desde Francia. Al cabo de tres años, el puente se concluyó en 1863.

Además de la detallada descripción del proceso de obra y el cálculo de la cimbra, los cables y demás medios auxiliares recogidos en la publicación de G. Martin (5), el cuaderno de A. Joly (12) es un valioso manuscrito. Consta de 29 páginas que a modo de diario, describen la construcción, con numerosos croquis e incidencias. El proceso constructivo quedó también documentado en las imágenes de Edouard Denis Baldus (Fi-

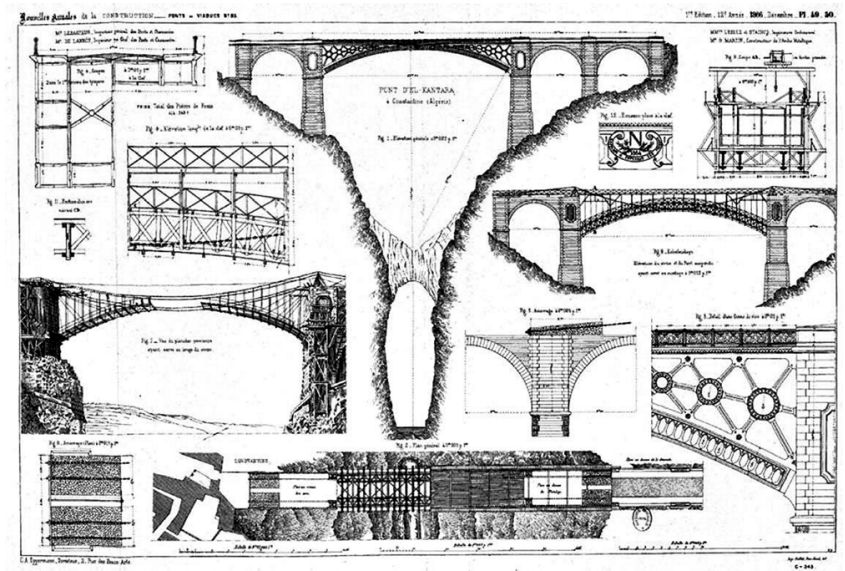

Figura 8. Proyecto y proceso constructivo del arco metálico de Napoleón III, 1863.

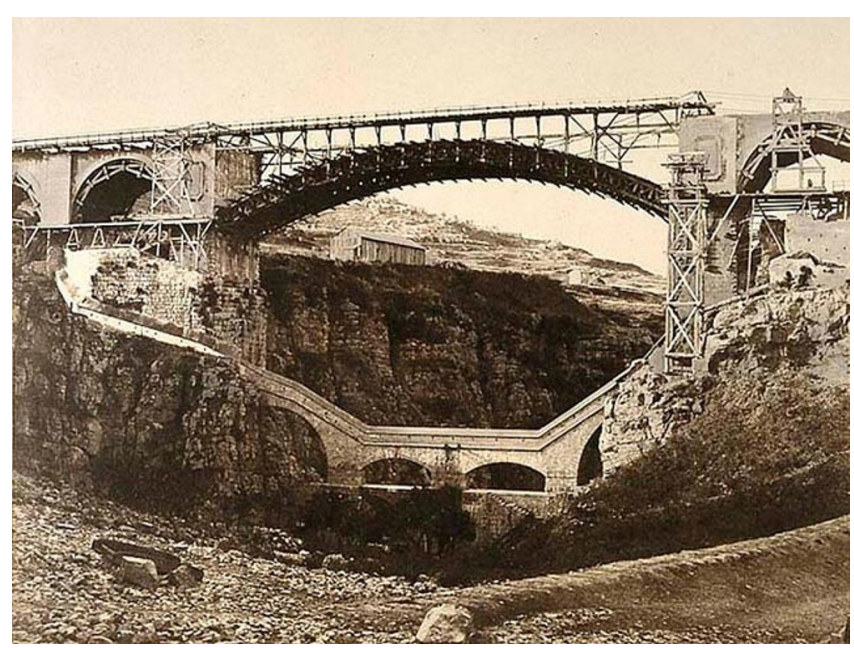

Figura 9. Construcción del puente de hierro. Fotografía: Edouard Denis Baldus, 1863.

gura 9), fotógrafo francés, cuyo trabajo testimonia la transformación del paisaje por la ingeniería moderna entre los años 1850 y 1869. El álbum dedicado al ferrocarril de París a Lyon es su trabajo más reconocido.

En 1950 uno de los arcos metálicos colapsó (Figura 10), afectando también a la conducción de abastecimiento.

\subsection{El puente de hormigón armado de El Kantara (1951)}

Tras el accidente, se retiraron el tablero y los arcos de hierro y se reconstruyó el vano central, con una estructura de hormigón armado Los viaductos de aproximación de fábrica se mantuvieron. La elección del hormigón armado como material resistente, en lugar de la estructura metálica, respondía a la solución unánime del momento. En la construcción, se aprovecharon las potentes pilas de fábrica de la estructura de 1863, y se mantuvo la directriz de los arcos.

En lugar de los cinco arcos de hierro, se dispusieron tres parejas de arcos de hormigón. Para centrar en la sección de fábrica de las pilas-estribo existente, los mayores empujes horizontales, debidos al incremento de peso de la nueva solución, se completó la coronación de las pilas con unos macizos de hormigón que añadían carga muerta. Un tablero esbelto se 


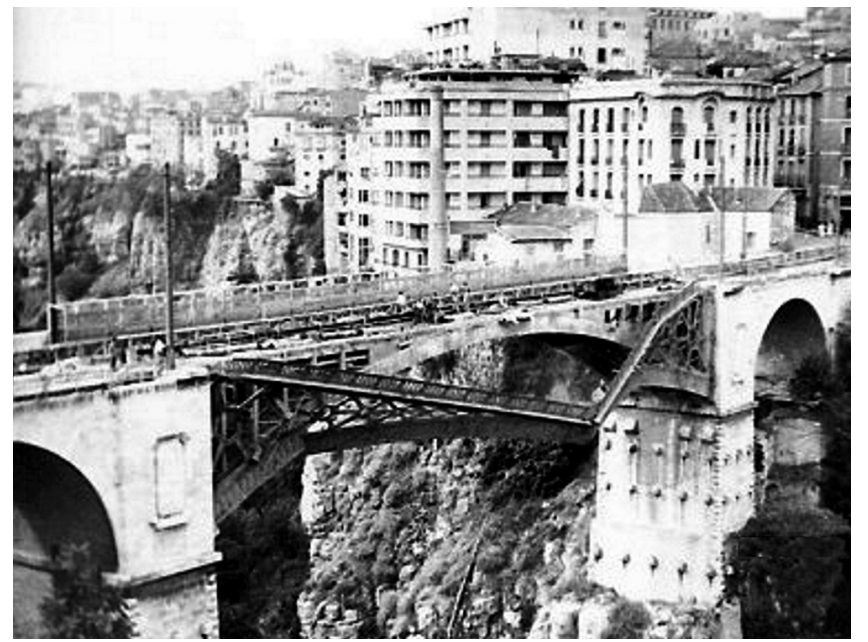

Figura 10. Colapso del arco exterior, 20 de septiembre de 1950.

apoya sobre pilas próximas de sección en $\mathrm{H}$, hasta empotrarse con el arco en clave. (Figura 11)

Durante la reconstrucción, se aprovechó para ensanchar el tablero, tanto la calzada como las aceras, para facilitar el tráfico rodado y la importante afluencia de peatones. Con reparaciones menores, esta estructura de 1951 actualmente sigue en servicio.

\section{EVOLUCIÓN TECNOLÓGICA, TRANSFORMACIÓN URBANA Y VALOR PATRIMONIAL}

La ingeniería del hierro supuso una transformación radical en la historia de la construcción. A su escala, el puente de El Kantara es un ejemplo modesto de la posibilidad de salvar luces mayores y aumentar la cota de la rasante de la plataforma, además de, en su caso, responder su reconstrucción a un plan de transformación urbana (Figura 7).

El barrio Bab El Kantara, aún hoy mantiene su nombre en relación al puente que le da acceso. El Kantara significa "puente» en árabe, mientras que $B a b$ es «puerta». También en España denominamos importantes puentes históricos como «puentes de Alcántara». El valor simbólico de la obra queda reforzado por su propia toponimia. Así, en Constantine, que mantiene el árabe y el francés, se denomina al puente como Pont d'El Kantara, es decir, "puente del puente», como una doble afirmación de su valor identitario.

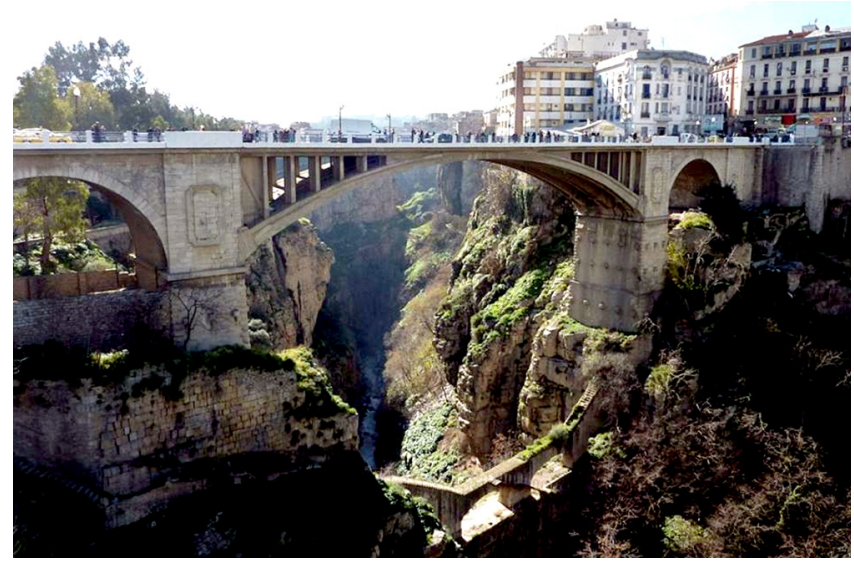

Figura 11. El puente de El Kantara en la actualidad.

Su relevancia monumental y simbólica se evidenció desde antiguo con las puertas que daban acceso a la ciudad (13). La puerta se erigió con el primer puente romano y se mantuvo en sus reconstrucciones posteriores. Los dos arcos de la reconstrucción de 1863 (Figura 6) supusieron, sin embargo, un cuello de botella para el tráfico, por lo que en 1922 se decidió su retirada, se buscó un nuevo emplazamiento testimonial sobre un lateral de la carretera de la Corniche, donde hoy se encuentra. También, en este caso, los ciudadanos de Constantine siguen refiriéndose a la porte Bab El Kantara, insistiendo en su representatividad: «la puerta puerta del puente».

\section{CONCLUSIONES}

El presente artículo recopila, ordena y relaciona documentación dispersa en relación al puente de El Kantara, con objeto de trazar su evolución histórica. Más allá de su relevancia tecnológica, esta construcción mantiene un importante valor cultural e identitario. A ello contribuyen, además, la idea de que constituye la primera comunicación estable de la ciudad sobre el Rhumel, la presencia de las ruinas históricas, la toponimia del lugar y, por supuesto, el constante uso cotidiano de su realidad construida.

Con el presente trabajo se aportan elementos para contribuir, especialmente en la ciudad de Constantine, a recuperar el legado de los puentes antiguos, tanto de los que perduran como de los que se perdieron, (14) (15), y para concienciar de la importancia de su mantenimiento y rehabilitación como valor cultural y patrimonio construido.

\section{REFERENCIAS}

(1) Meghraoui, N. (2011). Trois jours à Constantine, p. 148. Argel: Edition Dalimen.

(2) Meghraoui, N. (2004). Quel habitat pour l’Algérie?, p. 207. Constantine: Edition Media Plus.

(3) Al Idrisi. (1190). Kitab nuzhat al-mushtaq, p. 155. Argel: Edición de 1999 Bresc, H., Nef, A. (Traducción al francés Moukraenta Bakhta, 2005).

(4) Vars, Ch. (1893). Recueil des notices et mémoires de la société archéologique du département de Constantine. vol. 7 , serie 3, p. 372. Argel: Ed. Jourdan.

(5) Martin, G. (1865). Pont d'El Kantara à Constantine (Algérie), Notes, descriptions et dessins relatifs à la construction de l'échafaudage et de l'arche métallique, p. 46. París: Imp E.Thunot et Cp.

(6) Bernabéu Larena, J., Berrocal Menárguez, A., Aguiló Alonso, M. (2010). El legado compositivo de los puentes romanos. Revista de Obras Públicas, 157(3515): 53-66.

(7) Vars, Ch. (1893). Recueil des notices et mémoires de la société archéologique du département de Constantine. vol. 7 , serie 3, p. 311. Argel: Ed. Jourdan. 
(8) Maupassant, Guy de. (1850-1893). Carnets de Voyage: Au soleil, Sur l'eau, La Vie errante, p. 558. París : Editions G. Delaisement.

(9) Mercier, E. (1903). Histoire de Constantine. Constantine: J.Maele et F.Biron Imprimeurs-Editeurs.

(10) Cherbonneau. (1853). Recueil de l'annuaire de la société archéologique de la province de Constantine, p.145. Constantine: Imprimerie de F. Guende.

(11) Joleaud, L. (1937). Constantine: son passé, son centenaire (1837-1937). En Recueil des Notices et Mémoires de la Société archéologique de Constantine, Le ravin de Constantine, Vol. LXIV, p. 490. Constantine: Ed. Braham.

(12) Joly, A. (1863). Le pont d'El-Kantara à Constantine: Journal de mission. Collections patrimoniales des Ponts. http:// patrimoine.enpc.fr/document/ENPCo2_Ms_346.

(13) Côte, M. (2010). Constantine, cité antique et ville nouvelle, p. 155. Constantine: Ed. Média-Plus.

(14) Fernández Troyano, L. (1985). El patrimonio histórico de las obras públicas y su conservación: los puentes. Informes de la Construcción, 37(375): 5-55, doi: http://dx.doi.org/10.3989/ic.1985.v37.i375.1795.

(15) Plasencia-Lozano, P. (2014). Puentes, sociedad e ingeniería. Informes de la Construcción, 66(535): eo32, doi: http:// dx.doi.org/10.3989/ic.13.041. 